\title{
Effect of fraxetin on proliferation and apoptosis in breast cancer cells
}

\author{
GUODONG LIU $^{1 *}$, ZHENFANG LIU $^{1 *}$, YUEXIANG YAN ${ }^{1}$ and HAIYAN WANG ${ }^{2}$ \\ ${ }^{1}$ Department of General Surgery, Yidu Central Hospital of Weifang, Weifang, Shandong 262500; \\ ${ }^{2}$ Department of General Surgery, Weifang People's Hospital, Weifang, Shandong 261041, P.R. China
}

Received May 24, 2017; Accepted September 26, 2017

DOI: 10.3892/ol.2017.7143

\begin{abstract}
The aim of the present study was to examine the effect of fraxetin on proliferation and apoptosis in the MCF-7 breast cancer cell line. Cell proliferation was measused using an MTT assay and 4',6-diamidino-2-phenylindole (DAPI) staining was used to determine shrinkage and condensation. RT-PCR was used to examine the expression of factor-associated suicide (Fas) and Fas ligand (FasL) mRNA, and western blot analysis was used to examine Bax and Bcl-2 protein. MTT showed that the proliferation of MCF-7 cells was significantly inhibited by fraxetin in a dose-dependent manner. Fraxetin also induced significant morphological changes of MCF-7 cells, suggestive of apoptosis, whereas DAPI staining showed that fraxetin caused cell shrinkage and chromatin condensation. RT-PCR showed that the expression of Fas and FasL mRNA was upregulated by fraxetin and the western blot analysis revealed that Bax was upregulated and $\mathrm{Bcl}-2$ was downregulated. In conclusion, fraxetin can inhibit the proliferation of MCF-7 cells, induce apoptosis, upregulate Fas, FasL and Bax, and downregulate Bcl-2 to induce apoptosis. These results support the potential therapeutic role for fraxetin in breast cancer.
\end{abstract}

\section{Introduction}

Breast cancer is one of the most common malignancies in women. According to statistics, breast cancer accounts for $7-10 \%$ of all malignancies and is next only to uterine cancer in women (1). The pathogenesis of breast cancer is often related to genetic factors. Pre- and postmenopausal women between 40 and 60 years of age have the highest incidence and tumors are

Correspondence to: Dr Haiyan Wang, Department of General Surgery, Weifang People's Hospital, 151 Guangwen Street, Kuiwei, Weifang, Shandong 261041, P.R. China

E-mail:ckt44j@163.com

${ }^{*}$ Contributed equally

Key words: fraxetin, MCF-7 breast cancer cell line, proliferation and apoptosis, factor-associated suicide/factor-associated suicide ligand, Bax/Bcl-2 commonly originated in mammary gland epithelial tissue $(1,2)$. Statistical data published by WHO in 2008 indicated that new cases of breast cancer reached 1.38 million/year, ranking second among women. In addition, breast cancer accounted for $23 \%$ of new cases of cancer and ranked fifth in the causes of cancer death. Thus, breast cancer remains a serious threat to women's health $(3,4)$.

The existing clinical treatments for breast cancer usually have large adverse reactions, not only causing excruciating pain but also seriously reducing the quality of life. Chinese herbs have many advantages in traditional Chinese medicine. Its effective ingredients are characterized by high efficiency and low toxicity, and recently both domestic and foreign scientists have paid more attention to Chinese herbs due to these important advantages. The active ingredients from extracts of Chinese herbs play significant roles in inhibiting cancer cell proliferation, inducing apoptosis, and reducing the adverse effects of chemotherapy and radiotherapy (5). In recent years, Chinese herbs have become a hot spot due to minor side effects, anticancer and immune regulatory effects (6). Coumarin is a compound with the benzo- $\alpha$-pyrone nucleus that has many biological activities with broad medicinal value, including anticancer, immune support, antivirus, anti-bacterial, anti-oxidation, antiarrhythmic and anti-osteoporosis (7). Fraxetin is a simple coumarin compound and is an active ingredient of traditional Chinese medicine Cortex Fraxini. Fraxetin has received recent attention for its antitumor, antioxidation effects, as well as other pharmacological effects (8).

Bcl-2 can inhibit cell apoptosis and plays a critical role in the regulation of apoptosis. In addition, $\mathrm{Bcl}-2$ can protect cells from death, improve cell survival, and increase the number of cells (9). Bax and Bcl-2 belong to the same family, but Bax promotes apoptosis. Bax antagonizes the apoptosis inhibitory effect of $\mathrm{Bcl}-2$ gene and directly promotes cell apoptosis by interaction with cells (10). Factor-associated suicide (Fas) is a cell death factor that can induce apoptosis, and when Fas combines with the corresponding Fas ligand (FasL) on the cell surface, it activates an intracellular-related apoptotic signaling pathway $(11,12)$.

The aim of the current study was to investigate the effect of fraxetin on the proliferation and apoptosis of human breast cancer cells MCF-7. We examined the mechanism by which fraxetin induces apoptosis. This study lays the foundation for the clinical treatment of breast cancer. 


\section{Materials and methods}

Cell culture. MCF-7 breast cancer cells (Cell Bank, Chinese Academy of Sciences, Shanghai, China) were cultured at $37^{\circ} \mathrm{C}$ in $5 \% \mathrm{CO}_{2}$ until $85 \%$ confluence was reached. Then, the cells were digested with trypsin and cell suspension was diluted with Dulbecco's modified Eagle's medium (DMEM) (Gibco, Carlsbad, CA, USA) containing $10 \%$ fetal bovine serum. After cell concentration was adjusted to $2 \times 10^{8} /$ liter, the cells were counted and seeded in culture plates for the subsequent experiments.

Cell proliferation inhibition rate. Cell proliferation was measured using a 3-(4,5-dimethylthiazol-2-yl)-2,5-diphenyltetrazolium bromide (MTT) assay after cells were treated with fraxetin (both from Sigma, St. Louis, MO, USA). MCF-7 cells were seeded in 96-well plates at a concentration of $1 \times 10^{5} / \mathrm{ml}$ and each well contained $100 \mu \mathrm{l}$. After $24 \mathrm{~h}$, fraxetin was added to $10,20,40$ and $60 \mu \mathrm{M}$ final concentrations. The control group was treated without fraxetin. The cells were incubated for 24 and $48 \mathrm{~h}$ at $37^{\circ} \mathrm{C}$ in $5 \% \mathrm{CO}_{2}$ and then culture medium was changed. MTT $(10 \mu \mathrm{l})$ was added to each well at a final concentration of $5 \mathrm{mg} / \mathrm{ml}$. After incubating for $4 \mathrm{~h}$, the optical density (OD) at $570 \mathrm{~nm}$ was measured by a microplate reader (Bio-Rad Laboratories, Inc., Hercules, CA, USA). The inhibition rate was calculated as: Inhibition rate $(\%)=(\mathrm{OD}$ value of control group - OD value of experimental group/OD value of control group) x $100 \%$.

Morphological observation. MCF-7 cells were treated with 20,40 and $60 \mu \mathrm{M}$ of fraxetin for $24 \mathrm{~h}$, and the morphological changes were observed and recorded with an inverted microscope (Nikon, Tokyo, Japan).

4',6-Diamidino-2-phenylindole (DAPI) staining. MCF-7 cells were seeded in 6-well plates at a density of $1 \times 10^{4}$ cells/well. After $24 \mathrm{~h}$, the supernatant was suctioned and the cells were cultured in medium containing 20,40 or $60 \mu \mathrm{M}$ of fraxetin for $24 \mathrm{~h}$, then washed with pre-cooled phosphate-buffered saline (PBS) 3 times. DAPI solution $(1 \mu \mathrm{g} / \mathrm{ml})$ was added to each well, the cells were incubated at $37^{\circ} \mathrm{C}$ for $5 \mathrm{~min}$ and washed with pre-cooled PBS again. The cells were observed and images were captured using a fluorescence microscope (Nikon) in the dark.

Fas/FasL mRNA expression by RT-PCR. MCF-7 cells were seeded in 6 -well plates at a density of $1 \times 10^{4}$ cells/well. After $24 \mathrm{~h}$, the supernatant was suctioned and the cells were cultured in medium containing 20,40 or $60 \mu \mathrm{M}$ of fraxetin for $24 \mathrm{~h}$, the cells were collected and total RNA was extracted according to the instructions of the RNA extraction kit (Invitrogen, Carlsbad, CA, USA). RNA concentration and purity (A260/A280 >1.8, indicating pure RNA) were determined by UV-Vis spectrophotometer (Hitachi, Tokyo, Japan). cDNA was obtained via reverse transcription from mRNA according to the instruction of the reverse transcription kit (Invitrogen). The expression of target genes was then detected using cDNA as the template by RT-PCR assay, according to the manufacturer's instructions (Invitrogen), and glyceraldehyde 3-phosphate dehydrogenase $(G A P D H)$ was used as
Table I. Primer sequences for Fas/FasL.

\begin{tabular}{ll}
\hline Gene & \multicolumn{1}{c}{ Primer sequences } \\
\hline Fas & F: 5'-GGCATCTGGACCCTCCTACCTCTG-3' \\
& R: 5'-CCTTGGAGTTGATGTCAGTCACTTGG-3' \\
FasL & F: 5'- GGCCTGTGTCTCCTTGTGAT-3' \\
& R: 5'-TGCCAGCTCCTTCTGAAGTA-3' \\
GAPDH & F: 5'-ATGGCACCGTCAAGGCTGAG-3' \\
& R: 5'-GCAGTGATGGCATGGACTGT-3'
\end{tabular}

Fas, factor-associated suicide; FasL, factor-associated suicide ligand; F, forward; R, reverse.

an internal control. The primer sequences for Fas and FasL (Takara, Dalian, China) are shown in Table I. Amplification conditions were: $95^{\circ} \mathrm{C}$ for $10 \mathrm{~min}, 95^{\circ} \mathrm{C}$ for $15 \mathrm{sec}, 60^{\circ} \mathrm{C}$ for 1 min, with 40 cycles of amplification. The $\mathrm{Ct}$ value was automatically calculated using the CFX Manager software (Bio-Rad Laboratories, Inc.), and the relative quantification of gene expression was calculated using the $2^{-\Delta \mathrm{Ct}}$ method, as per the formula: $\Delta \mathrm{Ct}$ (target gene) $=\mathrm{Ct}$ (target gene) $-\mathrm{Ct}$ (control gene).

Bax and Bcl-2 protein expression by western blotting. MCF-7 cells were seeded in 6 -well plates at a density of $1 \times 10^{4}$ cells/well. After $24 \mathrm{~h}$, the supernatant was suctioned and the cells were cultured in medium containing 20,40 or $60 \mu \mathrm{M}$ of fraxetin for $24 \mathrm{~h}$. The cells were collected and lysed with cell lysis buffer (Biyuntian Biotechnology Research Institute, Nantong, China), centrifuged for $15 \mathrm{~min}$ at high speed and low temperature, and the supernatant was collected. The extracted protein concentrations were determined using a BCA protein quantification kit (Biyuntian Biotechnology Research Institute, Nantong, China). Subsequently, $50 \mu \mathrm{g}$ protein was separated by sodium dodecyl sulfate polyacrylamide gel electrophoresis (SDS-PAGE), and the proteins were transferred to a PVDF membrane. The membrane was incubated in blocking buffer for $1 \mathrm{~h}$ at room temperature and primary rabbit anti-huamn polyclonal antibodies against GAPDH, Bax and Bcl-2 (dilution, 1:1,000; cat. nos. 13937-1-AP, 23931-1-AP and 12789-1-AP; Sanying Biotechnology, Wuhan, China) were added and the membrane was incubated overnight at $4^{\circ} \mathrm{C}$. After washing the membrane with TTBS, HRP-conjugated goat anti-rabbit polyclonal secondary antibody (dilution, 1:2,000; cat. no. SA00001-2; Sanying Biotechnology) was added and the membrane was incubated at room temperature for $1 \mathrm{~h}$. Enhanced chemiluminescence (ECL) was added to the membrane and blots were developed in the dark. Images were recorded with a gel imaging system (Bio-Rad Laboratories, Richmond, CA, USA). GADPH was used as the internal reference, and the gray-scale values were analyzed and compared.

Statistical analysis. Data were presented as means \pm standard deviations. Data were analyzed by SPSS 17.0 (IBM Corp., Armonk, NY, USA) using one-way ANOVA along with multiple comparison test. $\mathrm{P}<0.05$ was considered statistically significant. 


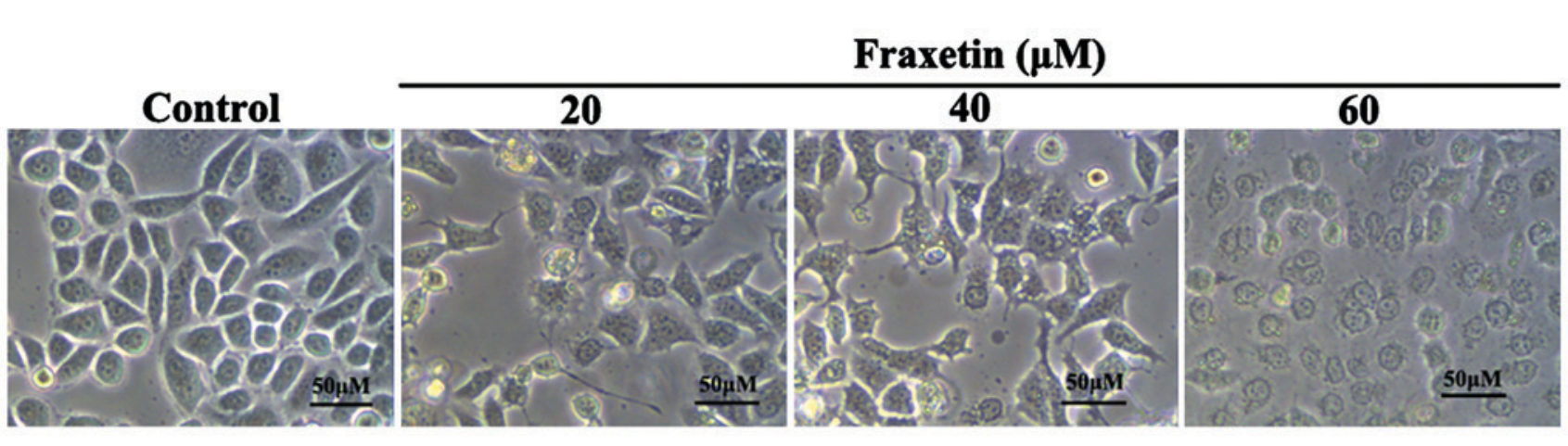

Figure 1. Effect of fraxetin on MCF-7 cell morphology. Changes of MCF-7 cell morphology, including cell shrinkage, decreased cell adherence, reduced cell number, and increased cell death number, were observed after treating cells with different concentrations of fraxetin for $24 \mathrm{~h}$. Morphological changes exhibited a significant dose-dependency.

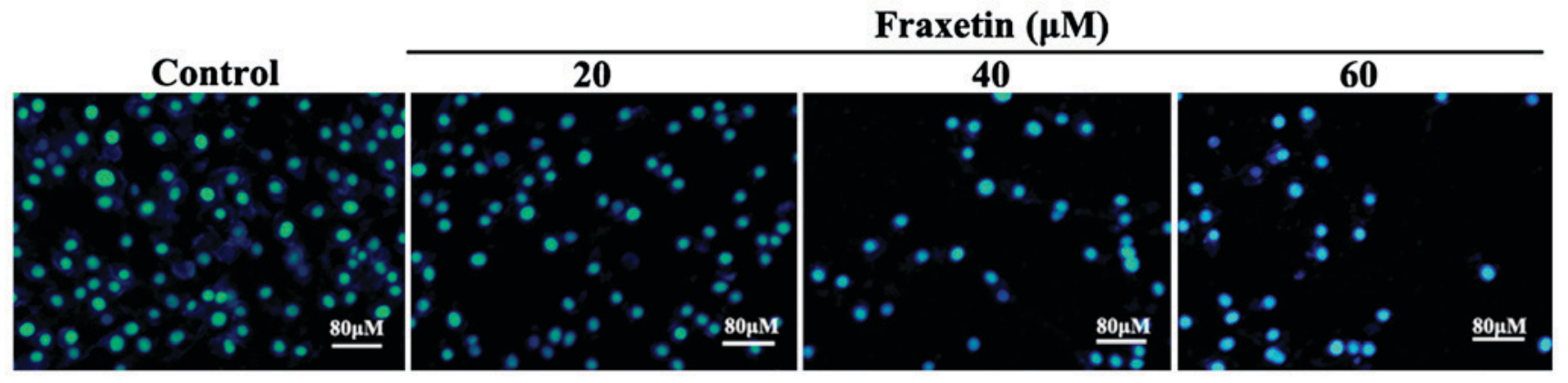

Figure 2. Effect of fraxetin on MCF-7 cell apoptosis. After MCF-7 cells were treated with different concentrations of fraxetin for $24 \mathrm{~h}$, cell shrinkage and chromatin condensation were observed indicating cell apoptosis.

\section{Results}

Effect of fraxetin on inhibition of MCF-7 cell proliferation. We first examined the ability of fraxetin to inhibit cell proliferation. MCF-7 cells were cultured in medium containing 0, 10, 20, 40 and $60 \mu \mathrm{M}$ of fraxetin. After $24 \mathrm{~h}$, the proliferation of MCF-7 cells was significantly inhibited in all the groups (Table II). The proliferation inhibition rates were obtained in a dose- and time-dependent manner (Table II). To examine the apoptotic mechanism, 20, 40 and $60 \mu \mathrm{M}$ of fraxetin were chosen as the drug concentrations and incubation time was $24 \mathrm{~h}$ for the subsequent experiments.

Effect of fraxetin on MCF-7 cell morphology. After MCF-7 cells were cultured for $24 \mathrm{~h}$ with $0,20,40$ and $60 \mu \mathrm{M}$ of fraxetin, the morphology of cells showed obvious changes. We observed cell shrinkage, decreased cell adherence, reduced cell number, and increased cell death number (Fig. 1). The changes in morphology exhibited dose-dependence.

Effect of fraxetin on cell apoptosis. After MCF-7 cells were cultured for $24 \mathrm{~h}$ with 20,40 and $60 \mu \mathrm{M}$ of fraxetin, DAPI staining showed cell shrinkage and nuclear chromatin condensation, suggesting the occurrence of apoptosis (Fig. 2). Moreover, the number of apoptotic cells increased with the increasing concentrations of fraxetin.

Effect of fraxetin on expression of Fas and FasL mRNA. The expression of Fas and FasL mRNA was significantly increased
Table II. Inhibitory effects of fraxetin on MCF-7 cell proliferation (mean $\pm \mathrm{SD})$.

\begin{tabular}{lcc}
\hline \multirow{2}{*}{$\begin{array}{l}\text { Fraxetin } \\
(\mu \mathrm{M})\end{array}$} & \multicolumn{2}{c}{ Cell proliferation inhibition rate $(\%)$} \\
\cline { 2 - 3 } & $24 \mathrm{~h}$ & $48 \mathrm{~h}$ \\
\hline 0 & 0 & 0 \\
10 & $9.25 \pm 0.12^{\mathrm{a}}$ & $12.32 \pm 1.13^{\mathrm{a}}$ \\
20 & $18.13 \pm 0.31^{\mathrm{a}}$ & $42.32 \pm 2.31^{\mathrm{a}}$ \\
40 & $35.67 \pm 1.32^{\mathrm{a}}$ & $58.22 \pm 2.28^{\mathrm{a}}$ \\
60 & $46.23 \pm 1.56^{\mathrm{a}}$ & $62.17 \pm 2.02^{\mathrm{a}}$
\end{tabular}

${ }^{\mathrm{a}} \mathrm{P}<0.01$ vs. the control group. $\mathrm{SD}$, standard deviation.

$(\mathrm{P}<0.01)$ after cells were incubated for $24 \mathrm{~h}$ with 20,40 and $60 \mu \mathrm{M}$ of fraxetin compared to the control cultured without fraxetin (Fig. 3).

Effect of fraxetin on Bax and Bcl-2 protein expression levels. After the cells were cultured for $24 \mathrm{~h}$ with 20, 40 and $60 \mu \mathrm{M}$ of fraxetin, the expression levels of Bax protein were significantly increased compared to the cells cultured without fraxetin $(\mathrm{P}<0.01)$. By contrast, the expression levels of $\mathrm{Bcl}-2$ were significantly decreased in the wells treated with fraxetin (Fig. 4). The expression levels of Bax and Bcl-2 changed in a dose-dependent manner. 
A

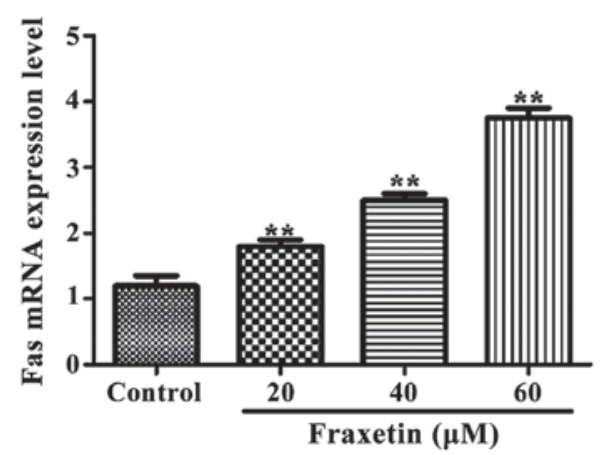

B

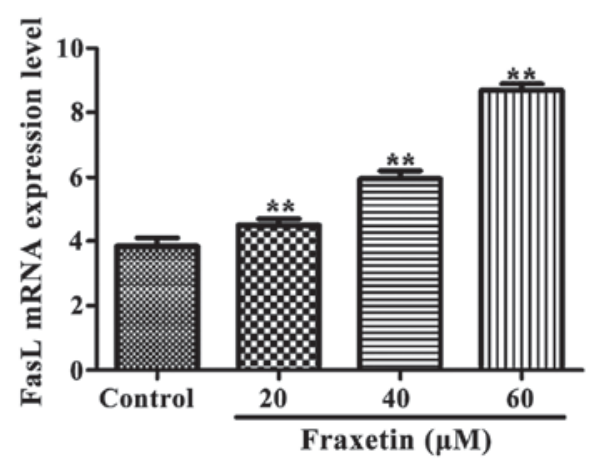

Figure 3. Effect of fraxetin on the expression of factor-associated suicide (Fas) and Fas ligand (FasL) mRNA. Compared with the control group, the expression levels of (A) Fas and (B) FasL mRNA were significantly increased in fraxetin-treated groups, ${ }^{* *} \mathrm{p}<0.01$.
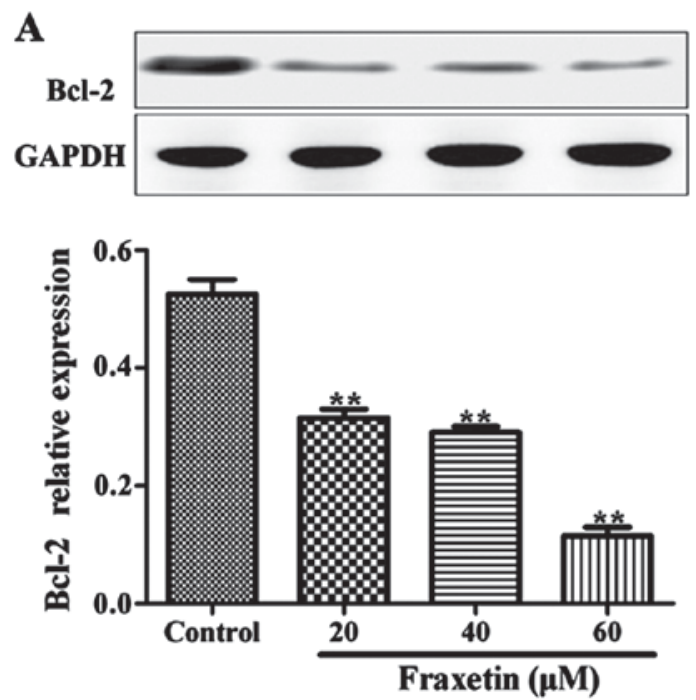
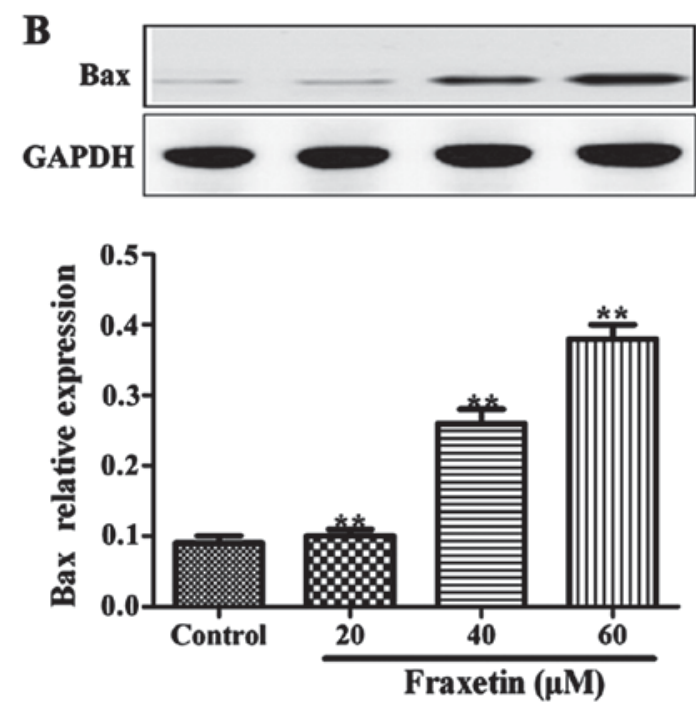

Figure 4. Effect of fraxetin on the expression levels of Bax and Bcl-2 in MCF-7 cells. (A) Bcl-2 and (B) Bax protein expression. Compared with the control group, the expression level of $\mathrm{Bcl}-2$ was significantly decreased, while that of Bax protein was significantly increased, ${ }^{* *} \mathrm{p}<0.01$.

\section{Discussion}

The increasing incidence of breast cancer makes it a serious threat to the lives of women and to their quality of life. Breast cancer cells are prone to drug resistance and adverse reaction to first-line chemotherapy drugs are obstacles to breast cancer treatment. Therefore, the choice of targeted therapy, the rationalization of individual treatment regimen, and the harm reduction in therapeutic drugs have been primary aims for breast cancer treatment (13). At present, drugs used for targeted therapy are lacking; therefore, effective drugs with low toxicity that are cost-effective have become a societal priority.

In some tumors, the upregulation of Bcl-2 protects cells from death or prolonged lifespan (14), indicating that Bcl-2 is critical for tumor survival. When Bcl-2 forms homodimers, it inhibits apoptosis. By contrast, Bax promotes apoptosis when its expression increases and binds Bcl-2 forming heterodimers or when Bax forms homodimers (15). Additionally, Bcl-2 downregulation induces apoptosis in multiple myeloma $(16,17)$. The abnormal expression of Fas/FasL is associated with a variety of diseases, including immune system diseases, tumor immunity, and transplantation immunity (18). The Fas/FasL signaling pathway also plays an important role in tumor inhibition: Fas expression is downregulated or lost in malignant tumor cells and when tumor cells are transformed, Fas is almost completely absent (19).

In the present study, we have shown that fraxetin significantly inhibited the proliferation of MCF-7 cells and induced morphological changes, including cell shrinkage and nuclear chromatin condensation. Additionally, fraxetin upregulated the expression of FasL and Fas mRNA. A positive expression of Fas found in non-small cell lung cancer tissues and normal tissues was 46.7 and $100 \%$, respectively $(20,21)$. Tumor cells avoid Fas/Fas-mediated apoptosis by downregulating the expression of Fas and preventing binding to its ligand FasL. Findings of that study are similar to those of the present study, further confirming that fraxetin can activate the apoptotic pathway and induce apoptosis of MCF-7 cells by upregulating the expression of Fas and FasL mRNA. Furthermore, fraxetin induced the expression of Bax while the expression of Bcl-2 was decreased, further inducing tumor cell apoptosis. 
The study by Xi et al (22) showed that carnosol induced Bax upregulation in leukemic cells and downregulation of Bcl-2 protein by $34-53 \%$.

In conclusion, the present study has demonstrated that fraxetin inhibits the proliferation of the MCF-7 breast cancer cell line and induces apoptosis of $\mathrm{MCF}-7$ cells. The induction of apoptosis may be achieved by upregulating FasL, Fas and Bax and downregulating $\mathrm{Bcl}-2$. In conclution, our results provide experimental support for the therapeutic effect of fraxetin on breast cancer.

\section{References}

1. Amatya B, Khan F and Galea MP: Optimizing post-acute care in breast cancer survivors: a rehabilitation perspective. J Multidiscip Healthc 10: 347-357, 2017.

2. McGurie WL: Breast cancer prognostic factors: Evaluation guidelines. Natl Cancer Inst 83: 154-155, 1991.

3. Abrahamsen JF, Bakken AM, Bruserud $\varnothing$ and Gjertsen BT: Flow cytometric measurement of apoptosis and necrosis in cryopreserved PBPC concentrates from patients with malignant diseases. Bone Marrow Transplant 29: 165-171, 2002.

4. Zwick E, Bange $J$ and Ullrich A: Receptor tyrosine kinase as targets for anticancer drugs. Trends Mol Med 8: 17-23, 2002.

5. Olaku $\mathrm{O}$ and White JD: Herbal therapy use by cancer patients: A literature review on case reports. Eur J Cancer 47: 508-514, 2011.

6. Jiménez-Orozco FA, López-González JS, Nieto-Rodriguez A, Velasco-Velázquez MA,Molina-Guarneros JA,Mendoza-PatiñoN, García-Mondragón MJ, Elizalde-Galvan P, León-Cedeño F and Mandoki JJ: Decrease of cyclin D1 in the human lung adenocarcinoma cell line A-427 by 7-hydroxycoumarin. Lung Cancer 34: 185-194, 2001

7. Finn GJ, Creaven BS and Egan DA: Daphnetin induced differentiation of human renal carcinoma cells and its mediation by p38 mitogen-activated protein kinase. Biochem Pharmacol 67: 1779-1788, 2004.

8. Kaneko T, Tahara S and Takabayashi F: Inhibitory effect of natural coumarin compounds, esculetin and esculin, on oxidative DNA damage and formation of aberrant crypt foci and tumors induced by 1,2 -dimethylhydrazine in rat colons. Biol Pharm Bull 30: 2052-2057, 2007.

9. Cory S, Huang DCS and Adams JM: The Bcl-2 family: Roles in cell survival and oncogenesis. Oncogene 22: 8590-8607, 2003.
10. Brady HJ and Gil-Gomez G: Bax. The pro-apoptotic Bcl-2 family member, Bax. Int J Biochem Cell Biol 30: 647-650, 1998.

11. Myong NH: Tissue microarray analysis of Fas and FasL expressions in human non-small cell lung carcinomas with reference to the p53 and bcl-2 overexpression. J Korean Med Sci 20: 770-776, 2005.

12. Chang JS, Hsu YL, Kuo PL, Chiang LC and Lin CC: Upregulation of Fas/Fas ligand mediated apoptosis by gossypol in an immortalized human alveolar lung cancer cell line. Clin Exp Pharmacol Physiol 31: 716-722, 2004.

13. Venditto VJ and Simanek EE: Cancer therapies utilizing the camptothecins: A review of the in vivo literature. Mol Pharm 7: 307-349, 2010.

14. Packham G and Cleveland JL: c-Myc and apoptosis. Biochim Biophys Acta 1242: 11-28, 1995.

15. Lu QL, Abel P, Foster CS and Lalani EN: bcl-2: Role in epithelial differentiation and oncogenesis. Hum Pathol 27: 102-110, 1996.

16. Kim SH, Ahn KS, Jeong SJ, Kwon TR, Jung JH, Yun SM, Han I, Lee SG, Kim DK, Kang M, et al: Janus activated kinase 2/signal transducer and activator of transcription 3 pathway mediates icariside II-induced apoptosis in U266 multiple myeloma cells. Eur J Pharmacol 654: 10-16, 2011.

17. Thoennissen NH, Iwanski GB, Doan NB, Okamoto R, Lin P, Abbassi S, Song JH, Yin D, Toh M, Xie WD, et al: Cucurbitacin B induces apoptosis by inhibition of the JAK/STAT pathway and potentiates antiproliferative effects of gemcitabine on pancreatic cancer cells. Cancer Res 69: 5876-5884, 2009.

18. Ryan AE, Shanahan F, O'Connell J and Houston AM: Fas ligand promotes tumor immune invasion of colon cancer in vivo. Cell Cycle 5: 246-249, 2006.

19. Korkolopoulou P, Saetta AA, Levidou G, Gigelou F, Lazaris A, Thymara I, Scliri M, Bousboukea K, Michalopoulos NV, Apostolikas N, et al: c-FLIP expression in colorectal carcinomas: Association with Fas/FasL expression and prognostic implications. Histopathology 51: 150-156, 2007.

20. Shimada H, Takeda A, Arima M, Okazumi S, Matsubara H, Nabeya Y, Funami Y, Hayashi H, Gunji Y, Suzuki T, et al: Serum p53 antibody is a useful tumor marker in superficial esophageal squamous cell carcinoma. Cancer 89: 1677-1683, 2000.

21. Law PT and Wong N: Emerging roles of microRNA in the intracellular signaling networks of hepatocellular carcinoma. J Gastroenterol Hepatol 26: 437-449, 2011.

22. Xi S, Kevin FD and Kimak M: Decreased SIRT1, expression by promoter methylation in squamous cell carcinogenesis. J Nat Cancer Inst 98: 181-189, 2006. 